\title{
Chemistry of mass-selected Au clusters deposited on sputter-damaged HOPG surfaces: The unique properties of $\mathrm{Au}_{8}$ clusters
}

\author{
Dong Chan Lim a, Rainer Dietsche ${ }^{\text {a }}$, Moritz Bubek ${ }^{\text {a }}$, Thorsten Ketterer ${ }^{\text {a }}$, \\ Gerd Ganteför ${ }^{a}$, Young Dok Kim ${ }^{b, *}$ \\ a Department of Physics, University of Konstanz, D-78457 Konstanz, Germany \\ ${ }^{\mathrm{b}}$ Division of Nano Sciences and Department of Chemistry, Ewha Womans University, 120-750 Seoul, Republic of Korea
}

\begin{abstract}
Mass-selected Au clusters consisting of less than 10 atoms were deposited on sputter-damaged HOPG surfaces. Oxidation and reduction of the $\mathrm{Au}$ clusters were studied using X-ray photoelectron spectroscopy. Only $\mathrm{Au}_{8}$ can be significantly oxidized by oxygen and reduced by $\mathrm{CO}$, and the result is different from those for Au clusters deposited on silica. The chemical properties of mass-selected clusters are dissimilar to those of Au nanoparticles larger $\sim 2-3 \mathrm{~nm}$. STM studies on $\mathrm{Au}_{7}$ suggest that $\mathrm{Au}_{7}$ exists as individual clusters rather than forming larger particles on the surface.
\end{abstract}

Since the discovery of high catalytic activity of Au nanoparticles, which is known to be inert as bulk, a large number of experimental and theoretical studies has been devoted for a better understanding of the size effects in heterogeneous catalysis of supported metal nanoparticles [1,2]. Among those studies, deposition of mass-selected clusters on various substrates opened new insights into the sizeselectivity of heterogeneous catalysis. Chemical properties were suggested to change with every additional atom $[3,4]$. Using scanning tunneling microscopy (STM), and cavity ring-down spectroscopy, deposited Au clusters on oxide surfaces were shown not to fragment or sinter $[5,6]$.

Here, oxidation and reduction of Au clusters deposited on sputter-damaged HOPG were studied. On silica surfaces, our previous studies found $\mathrm{Au}_{n}$ with $n=5$ and 7 to be resistant towards oxidation, whereas other clusters can readily be oxidized and reduced by $\mathrm{O}$ and $\mathrm{CO}$ [7]. In contrast, on sputtered HOPG, only $\mathrm{Au}_{8}$ was found to be active towards the oxidation/reduction, suggesting importance of

\footnotetext{
* Corresponding author.

E-mail address: ydkim@ewha.ac.kr (Y.D. Kim).
}

metal-support interaction for chemistry of deposited clusters [7]. Diverse chemical properties of mass-selected clusters are demonstrated, which cannot be observed from larger $\mathrm{Au}$ nanoparticles formed on the same substrate, addressing importance of the ability to control the cluster size on an atom-by-atom basis in order to tune catalytic activity [8].

Details of the experimental set-up and oxidation/reduction experiments can be found elsewhere [7]. The HOPG samples were outgassed at $800 \mathrm{~K}$ for longer than $12 \mathrm{~h}$. Subsequently, the HOPG surfaces were sputtered with a kinetic energy of $\mathrm{Ar}$ ions of $0.5 \mathrm{keV}$ for $20 \mathrm{~s}$, in order to create defect sites for stabilizing Au clusters on the surface (sample current during sputtering $=1-2 \mu \mathrm{A}$ ). The defect density is estimated to be less than $2 \%$ of a monolayer based on our previous results of $\mathrm{Au}$ island formation on similarly sputtered HOPG surface by deposition of Au atoms at room temperature $[8,9]$. For oxidation of the Au clusters, the chamber was backfilled by $\mathrm{O}_{2}$ with a pressure of $8 \times 10^{-5}$ Torr, and at the same time, a hot filament was placed in the near of the sample (referred to as 'atomic oxygen') [10]. The exposure time of each sample to atomic oxygen was $30 \mathrm{~min}$. This method is known to create atomic 
oxygen environments, even though existence of the excited molecular oxygen species cannot be completely excluded [10]. Our previous studies on reactions between atomic oxygen and $\mathrm{Au}$ nanoparticles suggest that our oxidation condition is as severe as the oxygen plasma used in other groups $[11,12]$. Without hot Pt-filament, no oxidation of Au clusters could be observed.

High-temperature oxygen treatment of a sputtered HOPG surface leads to the formation of large pits, resulting from etching of carbon atoms by oxygen [13]. It is not clear yet, whether the carbon surface is significantly etched by atomic oxygen at room temperature or not. We found increase of the $\mathrm{C}-\mathrm{O}$ and $\mathrm{C}=\mathrm{O}$ bonds upon atomic oxygen exposure [14]. The difference between our experimental conditions and those used in Ref. [13] might be that we used a lower sample temperature so that accumulation of oxygen on the sputtered HOPG surface instead of etching of surface carbon atoms by $\mathrm{CO}$ or $\mathrm{CO}_{2}$ formation can be found in our case.

Fig. 1 demonstrates the $\mathrm{Au} 4 \mathrm{f}$ core level spectra of $\mathrm{Au}_{n}$ clusters deposited on sputter-damaged HOPG surfaces. $1 \times 10^{13}$ clusters were deposited on the surface (the surface area for the deposition of clusters is estimated to be $\sim 3 \times 3 \mathrm{~mm}^{2}$ ), estimated by measuring sample current during deposition. The background pressure of the chamber was better than $1 \times 10^{-9}$ mbar during deposition, and the
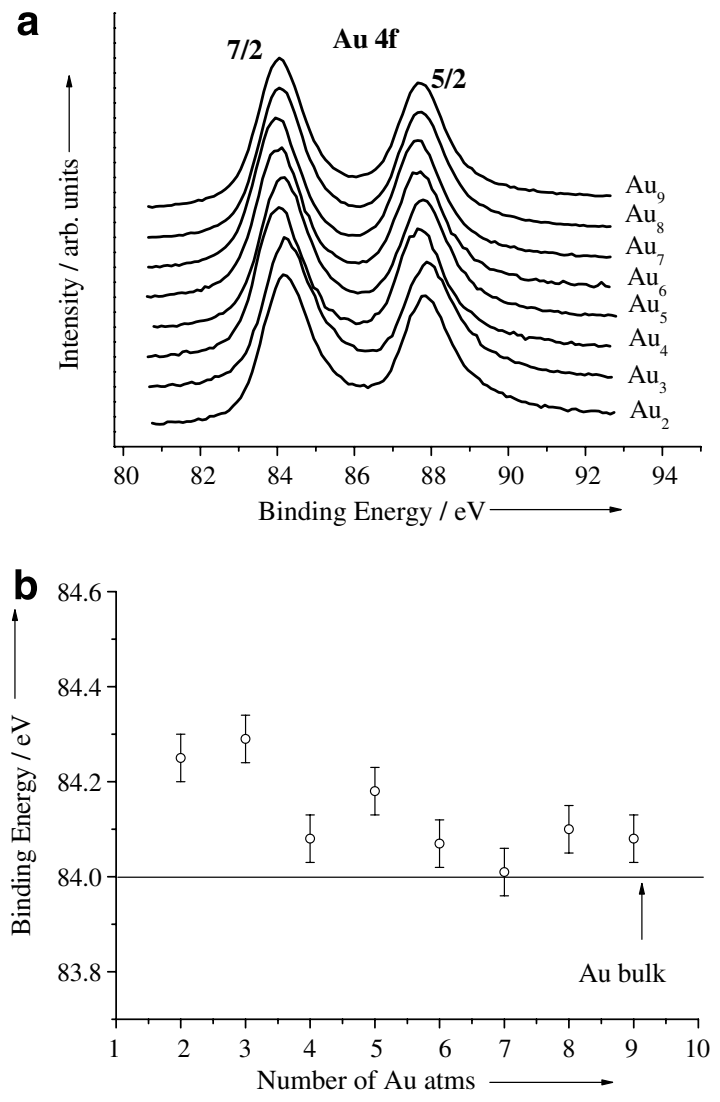

Fig. 1. Au $4 \mathrm{f}$ states of the deposited Au clusters on sputter-damaged HOPG. (a) $\mathrm{Au} 4 \mathrm{f}$ states of $\mathrm{Au}_{n}$ with $n=2-9$. (b) Summary of the $A u 4 \mathrm{f}_{7 / 2}$ binding energies as a function of cluster size. kinetic energy of a cluster during deposition was lower than $0.2 \mathrm{eV}$ per atom. Since no information is available for the sticking probability of $\mathrm{Au}$ clusters on sputter-damaged HOPG surfaces, the Au coverage cannot be precisely determined. Our XPS and also STM results are suggestive of an Au coverage of less than $\sim 10 \%$ of a monolayer equivalent in case of $\mathrm{Au}_{7}$. STM result also suggests that the sputtered surface is still quite flat, i.e. the surface consists of relatively flat terraces with point defects. The size dependent changes of the $\mathrm{Au} 4 \mathrm{f}_{7 / 2}$ binding energies are also summarized in Fig. 1, in which almost bulk-like binding energies of the $\mathrm{Au} 4 \mathrm{f}$ levels were observed. This result is in line with our previous data on Au nanoparticles on sputtered HOPG [9].

$\mathrm{Au}$ clusters on HOPG were exposed to atomic oxygen environments and subsequently, the $\mathrm{Au} 4 \mathrm{f}$ spectra were collected. When the $\mathrm{Au} 4 \mathrm{f}$ spectra of the bare $\mathrm{Au}_{n} / \mathrm{HOPG}$ surfaces in Fig. 1 are compared to the data of the respective $\mathrm{Au}_{n} / \mathrm{HOPG}$ samples acquired after atomic oxygen exposure in Fig. 2, the following can be found: for all clusters with one exception, only minor changes are observed after exposure to atomic oxygen. Only $\mathrm{Au}_{8}$ clusters are strongly oxidized, evidenced by additional peaks at higher binding energies. For $\mathrm{Au}_{2}$ and $\mathrm{Au}_{3}$, the $\mathrm{Au} 4 \mathrm{f}$ peaks become slightly narrower after oxygen treatment. For $\mathrm{Au}_{4}$, oxygen exposure induces a slight negative $\mathrm{Au} 4 \mathrm{f}$ level shift. For $\mathrm{Au}_{n}$ with $n=5-7,9$ no change in the Au $4 \mathrm{f}$ level can be found upon the oxygen treatment. It is important to note that no change in the metal core level does not necessarily indicate absence of $\mathrm{Au}-\mathrm{O}$ formation.

When the deposited $\mathrm{Au}$ clusters exposed to atomic oxygen are subsequently reacted with $\mathrm{CO}(3000 \mathrm{~L}, 1 \mathrm{~L}=$ $1 \times 10^{-6}$ Torr $\times 1 \mathrm{~s}$ ), changes of the $\mathrm{Au} 4 \mathrm{f}$ states can be found only for $\mathrm{Au}_{4}$ and $\mathrm{Au}_{8}$. For $\mathrm{Au}_{4}, \mathrm{Au} 4 \mathrm{f}$ peaks shift to the higher binding energy side, recovering the original $\mathrm{Au}$ 4f binding energies. The distinct $\mathrm{Au}(\mathrm{III})$ states appeared after oxygen treatment of deposited $\mathrm{Au}_{8}$ clusters are completely removed by $\mathrm{CO}$ exposure.

The $\mathrm{O} 1 \mathrm{~s}$ spectra collected from the samples of Fig. 2 are displayed in Fig. 3. The interpretation of the $\mathrm{O}$ 1s spectra is rather complicated: the sputter-damaged HOPG takes some oxygen, forming $\mathrm{C}-\mathrm{O}$ and $\mathrm{C}=\mathrm{O}$ species. These two different oxygen species bound to carbon show the $\mathrm{O} 1 \mathrm{~s}$ states at 531 and $533 \mathrm{eV}$, respectively $[8,15]$. An $\mathrm{O} 1 \mathrm{~s} \mathrm{spec}-$ trum obtained from an oxygen-treated sputtered HOPG surface is displayed in Fig. 3 (squares in the frame of $\mathrm{Au}_{8}$ ) for comparison. In addition, various $\mathrm{Au}-\mathrm{O}$ species may exist, which are electronically and also chemically different. We have previously shown that oxygen treatment of $\mathrm{Au}$ nanoparticles on sputtered HOPG surfaces results in formation of at least two electronically and chemically different oxygen species bound to $\mathrm{Au}[8,12]$. Although the assignment of the $\mathrm{O} 1 \mathrm{~s}$ spectra is complicated, the data in Fig. 3 clearly show that the chemical properties of the $\mathrm{Au}_{n} / \mathrm{HOPG}$ surfaces are very sensitive to the size of the clusters deposited. Only for $n=8$ a pronounced change indicating oxidation of $\mathrm{Au}$ is clearly observed. The results in Fig. 3 can be summarized as below: 


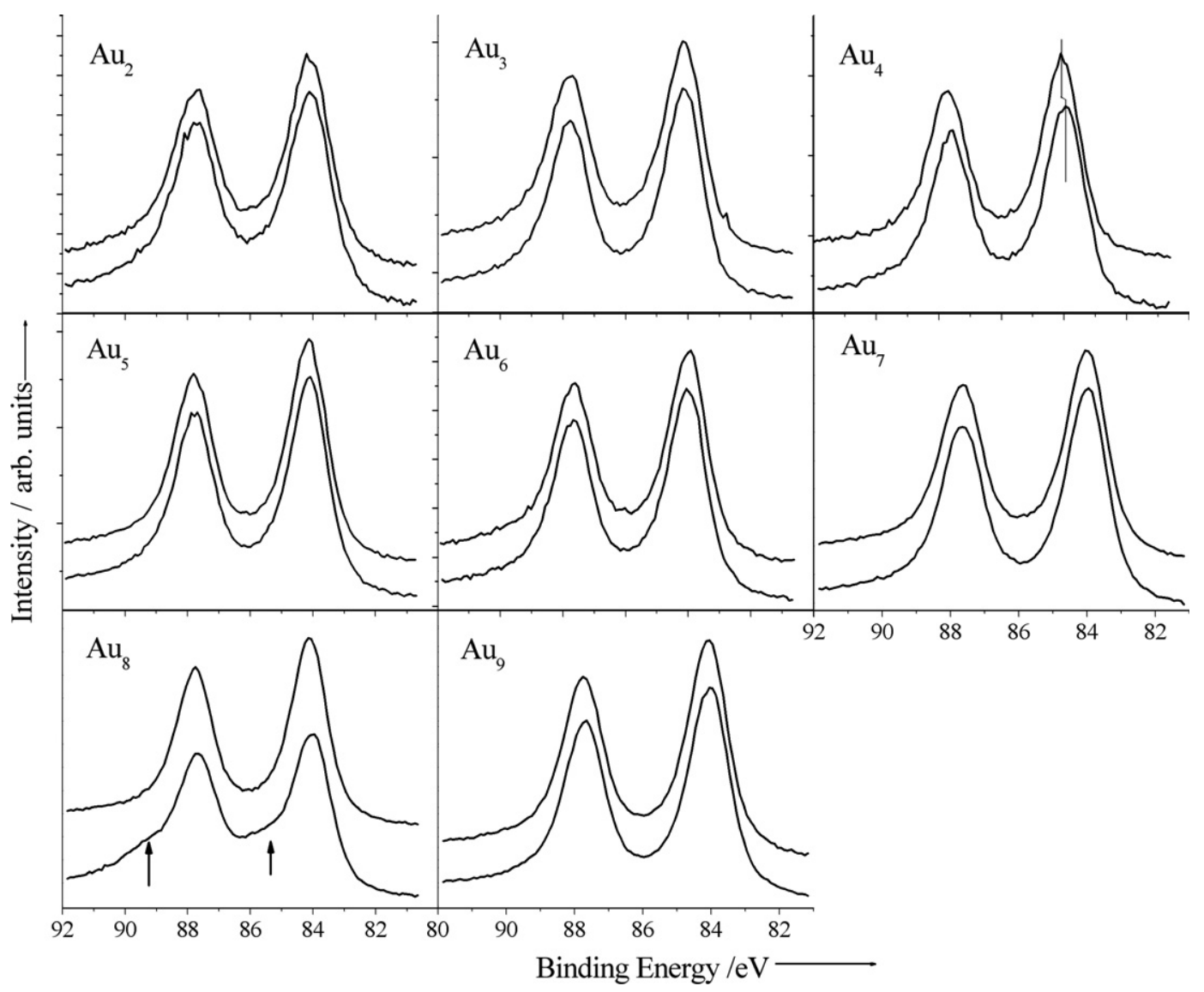

Fig. 2. The $\mathrm{Au} 4 \mathrm{f}$ spectra of the deposited $\mathrm{Au}_{n}$ clusters with $n=2-9$ after atomic oxygen exposure (first spectrum of each graph from the bottom), and after subsequent $\mathrm{CO}$ exposure are displayed.

(i) For $n=3,7,9$, a broad peak centered at $\sim 533 \mathrm{eV}$ can be observed in the $\mathrm{O}$ 1s spectra after exposing the surfaces to atomic oxygen environments. For these clusters, a subsequent $\mathrm{CO}$ exposure does not result in any change of the O 1s and Au 4f spectra. Since the O 1s state at $533 \mathrm{eV}$ is more pronounced than in the case of the oxygen-treated bare sputtered HOPG surface, the $533 \mathrm{eV}$ peak for these samples should mostly be related to the oxygen species attached to $\mathrm{Au}$, which is inert towards CO-oxidation. The nature of this inactive oxygen species is not clear. Oxygen species can be inert towards $\mathrm{CO}$-oxidation either due to the fact that oxygen occupies the same adsorption site as $\mathrm{CO}$, inhibiting the Langmuir-Hinshelwood type CO-oxidation, or oxygen has a too high binding energy [11]. Formation of carbonate species by the reaction between $\mathrm{Au}$, oxygen and carbon from substrate may be also one possible explanation for the existence of inert oxygen species of $\mathrm{Au}$ [14]. Since this oxygen species does not lead to the core level shift, the $\mathrm{Au}-\mathrm{O}$ bond nature should be rather covalent than highly ionic.

(ii) For $n=2,6$, a peak centered at $533 \mathrm{eV}$ with a shoulder at $531 \mathrm{eV}$ can be found in the $\mathrm{O} 1 \mathrm{~s}$ spectra. The absolute intensities of the $\mathrm{O}$ 1s spectra of these sam- ples are larger than that of the bare sputtered HOPG surface after the same oxygen treatment. No CO-oxidation takes place in this case.

(iii) For $\mathrm{Au}_{5}$, the relative intensity of the shoulder at $531 \mathrm{eV}$ with respect to other peaks becomes larger than in other cases mentioned above. Here again, no indication for CO-oxidation can be observed.

(iv) For $\mathrm{Au}_{4}$, formation of $\mathrm{Au}-\mathrm{O}$ species upon oxygen treatment and removal of some oxygen (characterized by the $\mathrm{O} 1 \mathrm{~s}$ state at $530 \mathrm{eV}$ ) by $\mathrm{CO}$ can be observed in the $\mathrm{O} 1 \mathrm{~s}$ spectrum, even though most of oxygen remains unreacted. The Au 4f spectra in Fig. 2 also show negative and positive shifts by $\mathrm{O}$ and $\mathrm{CO}$ treatments, in line with the $\mathrm{O} 1 \mathrm{~s}$ data in Fig. 3.

(v) For $\mathrm{Au}_{8}$, the shoulder at $530 \mathrm{eV}$ is more pronounced, which is reduced by $\mathrm{CO}$. The $\mathrm{O} 1 \mathrm{~s}$ peak at $530 \mathrm{eV}$ can be assigned to oxygen atoms attached to $\mathrm{Au}(\mathrm{III})$. After exposing the oxidized $\mathrm{Au}_{8}$ clusters to $\mathrm{CO}$, the $\mathrm{O} 1 \mathrm{~s}$ spectrum becomes identical to that of the bare substrate.

We have shown that $\mathrm{Au}_{5}$ and $\mathrm{Au}_{7}$ on silica are inert towards oxidation, whereas other Au clusters smaller than $\mathrm{Au}_{11}$ are able to be oxidized and reduced by $\mathrm{O} / \mathrm{CO}$ [7]. In the present work, $\mathrm{Au}_{8}$ was found to be the only cluster, 


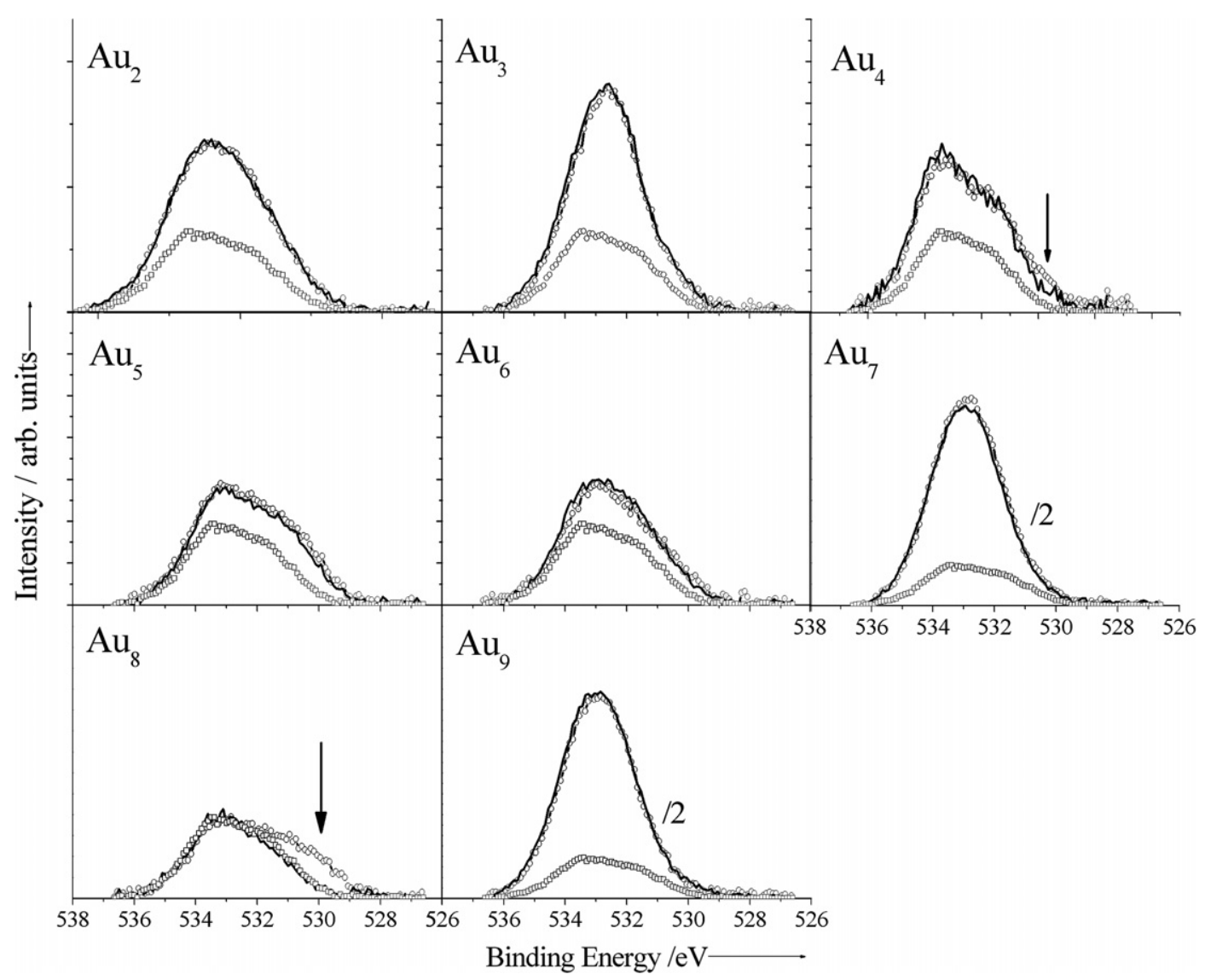

Fig. 3. O 1s spectra of the deposited $\mathrm{Au}_{n}$ clusters with $n=2-9$ after atomic oxygen exposure (line with circles), and after subsequent $\mathrm{CO}$ exposure (solid) are displayed. A O 1s spectrum collected from a bare sputtered HOPG exposed to the same amount of atomic oxygen is shown for comparison (line with squares). After exposing the oxidized $\mathrm{Au}_{8} / \mathrm{HOPG}$ to $\mathrm{CO}$, the $\mathrm{O}$ 1s spectrum becomes nearly identical to that of $\mathrm{O} / \mathrm{HOPG}$. Absolute intensities of all the $\mathrm{O}$ $1 \mathrm{~s}$ spectra shown here were normalized based on the $\mathrm{C} 1 \mathrm{~s}$ spectrum of each sample. The $y$-scale of each spectrum has been normalized, so that the absolute intensities of different spectra can be directly compared. The intensities of the $\mathrm{O} 1 \mathrm{~s}$ spectra of $\mathrm{Au}_{7}$ and $\mathrm{Au}_{9}$ and the respective spectra from bare $\mathrm{O} / \mathrm{HOPG}$ were divided by 2 .

showing a significant activity for the oxidation and reduction. We have shown that the chemical properties of deposited clusters are very sensitive to the substrate. Since $\mathrm{Au}$ nanoparticles on HOPG larger than 2-3 nm can form Au-oxide by the same oxygen treatment as used in the present work, which can be reduced by $\mathrm{CO}$, one may argue that the $\mathrm{Au}_{8}$ clusters sinter significantly forming larger particles instead of existing as individual clusters [8]. However, our $\mathrm{O}$ 1s spectra unambiguously show that the chemical properties of the mass-selected deposited clusters are very unique and much different from the larger $\mathrm{Au}$ nanoparticles: when larger $\mathrm{Au}$ nanoparticles are oxidized, two different oxygen species form, one of which is active towards CO-oxidation, and the other one is not [8]. In contrast, $\mathrm{Au}_{8}$ forms exclusively active oxygen species as shown in Fig. 3. Accumulation of catalytically inactive oxygen species can poison the catalysts, and $\mathrm{Au}_{8}$ on carbon may not experience this problem, which is different from other $\mathrm{Au}$ clusters and larger nanoparticles. This result shows that optimization of catalytic activity can be achieved by the control of the cluster size on an atomicby-atom basis.
Besides $\mathrm{Au}_{8}$, other clusters studied here also show chemical properties different from those of larger Au nanoparticles [8]. $\mathrm{Au}_{4}$ clusters show negative and positive shifts of the $\mathrm{Au} 4 \mathrm{f}$ states without $\mathrm{Au}(\mathrm{III})$ species formation upon $\mathrm{O} / \mathrm{CO}$ exposure, which has never been observed for larger $\mathrm{Au}$ nanoparticles on HOPG. Note that relatively small $\mathrm{Au}$ nanoparticles show a negative core level shift upon oxygen treatment, yet no positive shift upon $\mathrm{CO}$ exposure [12]. Furthermore, the $\mathrm{O} 1 \mathrm{~s}$ spectra of $\mathrm{Au}_{n}$ with $n=2,3,6,7$, 9 showing a pronounced feature centered at $533 \mathrm{eV}$, are much dissimilar to the respective data from larger $\mathrm{Au}$ nanoparticles (Fig. 3) [8]. For $\mathrm{Au}_{5}$, the $\mathrm{O}$ 1s state centered at $530-531 \mathrm{eV}$ is not reduced by $\mathrm{CO}$, whereas for larger $\mathrm{Au}$ nanoparticles, the $\mathrm{O} 1 \mathrm{~s}$ state at the same binding energy range is essentially removed by $\mathrm{CO}$ at room temperature. All these results demonstrate unique chemical properties of the mass-selected deposited Au clusters, and indicative of the mass-selected clusters not sintering but rather surviving as individual clusters on the surface after deposition on the sputter-damaged HOPG surfaces.

The idea of an $\mathrm{Au}$ cluster surviving as an individual entity is also supported by our STM results. As shown in 

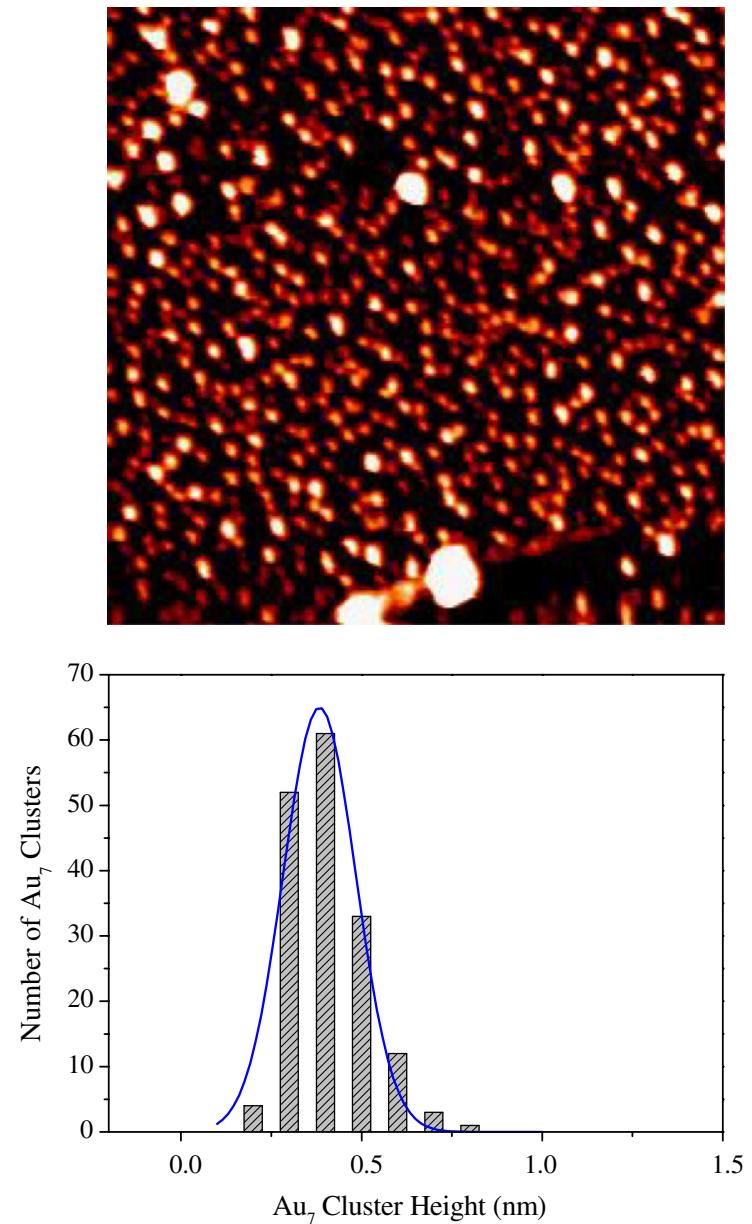

Fig. 4. STM images of $\mathrm{Au}_{7}$ deposited on sputter-damaged HOPG $(150 \mathrm{~nm} \times 150 \mathrm{~nm}, 1.61 \mathrm{~V}, 0.7 \mathrm{nA})$. Statistics of the cluster height is shown in the bottom image. The cluster height is $0.38 \pm 0.1 \mathrm{~nm}$.

Fig. 4, the STM image of $\mathrm{Au}_{7}$ clusters deposited on sputtered HOPG exhibits many particles distributed on the surface with a very narrow size distribution. The average particle height is about $0.4 \mathrm{~nm}$, corresponding to two atomic layers. The particle diameter is subject to the particle-tip convolution and therefore cannot be determined precisely; one may roughly suggest that the cluster diameter in Fig. 4 should be smaller than $2 \mathrm{~nm}$. In the STM image of Fig. 4, a few larger particles can be found near to vacant areas, which we tentatively suggest to be due to the agglomeration of the clusters induced by the STM tip.

In summary, we found a significant size-dependent change of the chemical properties of mass-selected $\mathrm{Au}$ clusters deposited on sputtered HOPG. The chemical properties of mass-selected clusters consisting of less than 10 atoms are found to be much different from those of larger nanoparticles. Results from $\mathrm{Au}$ clusters deposited on carbon and silica demonstrate importance of metal-support interactions for tuning chemical activity of metal clusters.

\section{Acknowledgement}

We acknowledge Deutsche Forschungsgemeinschaft (DFG) for financial supports within the SFB 513 program (Project number A 15). This work was supported by the Ewha Womens University Research Grant of 2006.

\section{References}

[1] M. Haruta, S. Tsubota, T. Kobayashi, H. Kageyama, M.J. Genet, B. Delmon, J. Catal. 144 (1993) 175.

[2] R. Meyer, C. Lemire, Sh.K. Shaikhutdinov, H.-J. Freund, Gold Bull. 37 (2004) 72 .

[3] A. Sanchez, S. Abbet, U. Heiz, W.-D. Schneider, H. Häkkinen, R.N Barnett, U. Landman, J. Phys. Chem. A 103 (1999) 9573.

[4] S. Lee, C. Fan, T. Wu, S.L. Anderson, J. Am. Chem. Soc. 126 (2004) 5682.

[5] X. Tong, L. Benz, P. Kemper, H. Metiu, M.T. Bowers, S.K. Buratto, J. Am. Chem. Soc. 127 (2005) 13516.

[6] J.M. Antonietti et al., Phys. Rev. Lett. 94 (2005) 213402.

[7] D.C. Lim, I. Lopez-Salido, R. Dietsche, M. Bubek, Y.D. Kim, Chem. Phys. Chem. 7 (2006) 1909.

[8] D.C. Lim, I. Lopez-Salido, R. Dietsche, Y.D. Kim, Surf. Sci. 598 (2005) 96.

[9] I. Lopez-Salido, D.C. Lim, R. Dietsche, Y.D. Kim, J. Phys. Chem. B 110 (2006) 1128.

[10] N.D.S. Canning, D. Outka, R.J. Madix, Surf. Sci. 141 (1984) 240.

[11] H.-G. Boyen et al., Science 297 (2002) 1533.

[12] D.C. Lim, I. Lopez-Salido, M. Bubek, R. Dietsche, Y.D. Kim, Angew. Chem. Int. Ed. 45 (2006) 2413.

[13] H. Hövel, Th. Becker, A. Bettac, B. Reihl, M. Tschudy, E.J. Williams, J. Appl. Phys. 81 (1997) 154.

[14] S.H. Jeong, D.C. Lim, J.-H. Boo, S.B. Lee, H.N. Hwang, C.C. Hwang, Y.D. Kim, Appl. Catal. A 320 (2007) 152.

[15] G. de la Puente, J.J. Pis, J.A. Menedez, P. Grange, J. Anal. Appl. Pyrol. 43 (1997) 125. 